\title{
GAS6 PROMOTES INFLAMMATION BY ENHANCING INTERACTIONS BETWEEN ENDOTHELIAL CELLS, PLATELETS AND LEUKOCYTES
}

Marc Tjwa ${ }^{1,2}$, Lola Bellido-Martin ${ }^{3}$, Yuan Lin $^{4}$, Esther Lutgens ${ }^{5}$, Stéphane Plaisance ${ }^{1,2}$, Françoise Bono ${ }^{6}$, Nathalie Delesque-Touchard ${ }^{6}$, Caroline Hervé $^{6}$, Rute Moura ${ }^{7}$, An Billiau $^{4}$, Cristina Aparicio ${ }^{8}$, Marcel Levi ${ }^{1,2}$, Mat Daemen ${ }^{5}$, Mieke Dewerchin ${ }^{1,2}$, Florea Lupu $^{8}$, Jef Arnout ${ }^{7}$, Jean-Marc Herbert ${ }^{6}$, Mark Waer ${ }^{4}$, Pablo García de Frutos ${ }^{3,9}$, Björn Dahlbäck $^{9}$, Peter Carmeliet ${ }^{1,2 \star}$, Marc F. Hoylaerts ${ }^{7}$ and Lieve Moons ${ }^{1,2}$.

1. Department for Transgene Technology and Gene Therapy, VIB, Leuven, Belgium.

2. Center of Transgene Technology and Gene Therapy, K.U.Leuven, Leuven, Belgium.

3. Instituto de Investigaciones Biomédicas de Barcelona, IIBB-IDIBAPS-CSIC, Barcelona, Spain.

4. Laboratory of Experimental Transplantation, K.U.Leuven, Leuven, Belgium.

5. Department of Pathology, University of Maastricht, Maastricht, The Netherlands.

6. Cardiovascular-Thrombosis Research Department, Sanofi Aventis, Toulouse, France.

7. Center for Molecular and Vascular Biology (CMVB), K.U.Leuven, Leuven, Belgium.

8. Cardiovascular Research Program, Oklahoma Medical Research Foundation, Oklahoma 73104, USA

9. Department of Clinical Chemistry, University of Lund, Malmo, Sweden.

Short title: Role of Gas6 in endothelial activation

Word count text: $\quad \pm 5,188$

Word count abstract: 94

Category: Hemostasis, Thrombosis, and Vascular Biology

*: corresponding author: Peter Carmeliet (peter.carmeliet@med.kuleuven.be)

Center for Transgene Technology \& Gene Therapy

Campus Gasthuisberg, Herestraat 49, box 912

B-3000, Leuven, Belgium

tel: +32-16-34.57.74; fax: +32-16-34.59.90 


\section{ABSTRACT}

The role of Gas6 in endothelial cell (EC) function remains incompletely characterized. Here, we report that Gas6 amplifies EC activation in response to inflammatory stimuli in vitro. In vivo, Gas 6 promotes and accelerates the sequestration of circulating platelets and leukocytes on activated endothelium as well as the formation and endothelial sequestration of circulating platelet-leukocyte conjugates. In addition, Gas6 promotes leukocyte extravasation, inflammation and thrombosis in mouse models of inflammation (endotoxinemia, vasculitis, heart transplantation). Thus, Gas6 amplifies EC activation, thereby playing a key role in enhancing the interactions between ECs, platelets and leukocytes during inflammation. 


\section{INTRODUCTION}

The growth arrest-specific gene 6 (Gas6) binds to the receptor tyrosine kinases Axl, Tyro3 and Mer ${ }^{1}$. Gas6 is composed of a N-terminal gamma-carboxy-glutamic acid domain (Gla-domain), a loop region, four EGF-like repeats, and a C-terminal steroid hormone binding globulin-like (SHBG-like) domain) ${ }^{1}$. Even though this molecule was discovered as a homologue of the anti-coagulant Protein $\mathrm{S}$ more than a decade ago, its role in vivo remains incompletely characterized ${ }^{2,3}$. Originally identified in fibroblasts, Gas 6 is expressed in various cell types, including endothelial cells (ECs) ${ }^{4}$, smooth muscle ${ }^{5}$, and bone marrow cells ${ }^{6}$. Gas6 and its receptors modify platelet activation and aggregation ${ }^{7-10}$, but the role of Gas6 in the interplay between platelets and other cell types, such as ECs and leukocytes ${ }^{11}$, during inflammatory conditions remains unclear.

Several lines of evidence indeed suggest that Gas6 may affect ECs and leukocytes. ECs and leukocytes express Gas6 and its receptors, especially in conditions of inflammation and repair ${ }^{4,12-16}$. Gas6 stimulates EC survival ${ }^{17-20}$ and promotes angiogenesis by enforcing the adhesion of Axl-expressing ECs via homophilic interactions 21-23, yet another study suggested that activation of $A x \mathrm{impairs}$ tyrosine phosphorylation of VEGF receptor-2 ${ }^{24}$. The activity of Gas6 on leukocytes also remains incompletely understood. Indeed, genetic loss of Mer inhibits cytokine production by natural killer cells ${ }^{25}$, while it stimulates TNF $\alpha$ production by monocytes ${ }^{14}$ and impairs clearance of apoptotic cells ${ }^{26}$. Loss of all three Gas6 receptors, on the other hand, induces lymphoproliferative disorders via hyperactivation of antigen-presenting cells ${ }^{27,28}$, but mice lacking Gas 6 $\left(\right.$ Gas6 $\left.^{-/}\right)$do not develop auto-immune health problems (unpublished). In humans, the plasma levels of Gas6 were found to be elevated during severe sepsis - a life-threatening condition involving increased interactions between ECs, leukocytes and platelets ${ }^{29,30}$. However, exogenous Gas6 inhibits granulocyte adhesion to ECs, but only at very high doses ${ }^{31}$. Furthermore, the role of endogenous Gas6 in leukocyte extravasation in vivo was not studied. Here, by using our previously generated Gas6 ${ }^{-/-}$mice ${ }^{7}$, we studied whether Gas6 might play a role in EC activation and in the interactions between ECs, platelets and leukocytes during inflammatory conditions. 


\section{EXPERIMENTAL METHODS}

\section{Mice}

The generation of Gas6 $^{-/-}$mice has been described ${ }^{7}$. The original line was back-crossed into a C57BL/6 background for more than 10 generations, yielding congenic C57BL/6 $\mathrm{Gas6}^{-/-}$mice. Housing and all experimental animal procedures were approved by the Institutional Animal Care and Research Advisory Committee of the K.U. Leuven.

\section{ELISA for mGas6}

An ELISA for murine Gas6 was developed using commercially available antibodies and standard (R\&D Systems).

\section{In vitro endothelial cell activation assays}

Primary mouse ECs were isolated from matrigel granulomas ${ }^{32}$. Production of Gas6 was determined after culturing $1 \times 10^{5}$ cells for $24 \mathrm{~h}$ in low serum containing culture medium. Expression of adhesion molecules and cytokines was determined as described ${ }^{33}$. In brief, ECs were plated at 2000 cells/well in 96-well tissue culture plates and grown at $37^{\circ} \mathrm{C}$ in $5 \% \mathrm{CO}_{2}$ for $24 \mathrm{hrs}$. At the time of the experiment, culture medium was removed and replaced by serum-free medium containing vehicle or recombinant mouse $(\mathrm{rm}) \mathrm{TNF} \alpha(100$ $\mathrm{ng} / \mathrm{ml}$; R\&D Systems). After 24 hours, cells were washed once with serum-free medium. Specific antibodies for mICAM-1 and mVCAM-1 (R\&D Systems) were added to each well and incubated at $37^{\circ} \mathrm{C}$ in $5 \% \mathrm{CO}_{2}$ for 1 to 2 hours. After incubation with a horseradish peroxidase-conjugated secondary antibody the HRP activity was determined. The data represent the mean \pm SEM of triplicates obtained from three different experiments. Levels of IL-6 and IL-1ß in the culture medium were measured using commercially available ELISAs (R\&D Systems). HUVECs were cultured in EGM medium (Cambrex) supplemented with hEGF and hydrocortisone. Fresh Heparine and ECGS (HE) were added at each passage. For electroporation with Gas6, Axl, Tyro3 or control siRNA (Qiagen), 90\% confluent HUVECs were nucleofected using the Nucleofector device 
(Amaxa Gmbh) according to the manufacturer's instruction (nucleofector program A-034). At 24 hours after nucleofection, HUVECs were stimulated for 24 hours with rhTNF- $\alpha$ (R\&D Systems) in medium without HE. Cell lysates were analyzed for hICAM-1 expression using a commercially available ELISA (R\&D Systems).

\section{In vivo study of platelet tethering, rolling and adhesion}

Videomicroscopy on mesenteric venules was performed as described with slight modifications ${ }^{34}$. Briefly, recipient C57BI6 WT or Gas6 ${ }^{-1-}$ mice were anesthetized with urethane $(1.4 \mathrm{mg} / \mathrm{kg})$ to maintain physiological blood pressure and heart rate, and the external jugular vein was cannulated for continuous venous access. Non-activated platelets of donor syngeneic WT or Gas6 ${ }^{-/-}$mice (1 donor per 1 recipient mouse) were fluorescent-labeled with calcein, and slowly infused via the catheter. Alternatively, rhodamine $6 \mathrm{G}(1 \mathrm{mg} / \mathrm{ml}$ in saline) was infused to label circulating cells in vivo; platelets and leukocytes were clearly distinguishable by size. Gallic acid (GA; $3.4 \mathrm{mg} / \mathrm{kg} / \mathrm{h}$ ), previously shown to selectively inhibit P-selectin, was continuously administered intravenously via an infusion pump, as described previously ${ }^{34,35}$. The mesentery of recipient mice was externalized and mesenteric venules were exposed on the table of an epifluorescence microscope for direct visualization under videomicroscopy. Local EC activation was induced via topical application of the calcium ionophore A23187 (10 $\mu$ at 30 $\mu \mathrm{M})$. Platelet activation was induced by i.v. bolus injection of collagen $(50 \mu \mathrm{g} / \mathrm{kg})$, combined with a $\alpha_{\| \mathrm{lb}} \beta_{3}$ antagonist (G4120, $1 \mathrm{mg} / \mathrm{kg}$ ) to prevent platelet aggregation. Movies were recorded 10 min after activation at 10 frames per sec, and analyzed post-hoc using NIH image 1.62 software. For kinetic analysis, movies with a duration of 1 min were recorded at indicated time points. The following criteria were used: cells were tethering/rolling when a clear cell/stripe was present on 3 or more consecutive frames; cells were adhering/arrested when a clear arrest of cells was present on 2 or more consecutive frames; conjugates were interacting when a clearly more intense fluorescence signal containing at least 2 separately identifiable platelets was present on 3 or more 
consecutive frames. Data were expressed as cells per min. The mean number of infused platelets $\left( \pm 50 \times 10^{6}\right.$ in $\left.200 \mu \mathrm{l}\right)$ and the sizes of the analyzed mesenteric venules (120-150 $\mu \mathrm{m}$ diameter) were not different between genotypes. Determination of Weibel-Pallade body count and FACs analysis are described in the supplemental methods.

\section{In vivo model of endothelial cell activation}

Mice were injected i.p. with a sublethal dose of recombinant mouse TNF- $\alpha(100 \mu \mathrm{g} / \mathrm{kg}$;

R\&D Systems), hearts were harvested after 24 hours and immediately embedded in Tissue-Tek in liquid nitrogen-cooled 2-methylbutane. Seven $\mu \mathrm{m}$ sagittal sections were briefly fixed in aceton and immunostained with a biotinylated rat anti-VCAM-1 (1:50, BD Biosciences) or a rat anti-ICAM-1 antibody (CD54, 1:100, Seikagaku). Tissues were stained by amplification with the tyramide signal amplification system (Perkin Elmer, Life Sciences) using 3,3'-diaminobenzidine (DAB, Sigma) as a chromogen substrate and counterstained with Harris hematoxilin.

\section{Animal models}

All animal models are described in the supplemental methods.

\section{Statistical analysis}

SPSS 11.0 was used for statistical analysis and $P$-values were calculated using unpaired student's t-tests, ANOVA or Fisher's exact analyses. Data are represented as mean \pm SEM and were considered statistically significant at $P<0.05$. 


\section{RESULTS}

\section{Endothelial CELLS RELEASE GAS6}

Gas6 is present in mouse blood plasma ${ }^{36}$; recent reports suggest that endothelial cells (ECs), which express Gas6 ${ }^{4}$, might be a potential source of plasma Gas6 ${ }^{29,37}$. By ELISA, Gas6 was indeed detectable in plasma of wild type (WT) mice $(29 \pm 2 \mathrm{ng} / \mathrm{ml})$ but not in $\mathrm{Gas}^{-/-}$mice. Gas6 was also detectable in murine platelets $\left(28 \pm 3 \mathrm{pg} / 10^{6}\right.$ platelets), but undetectable in erythrocyte lysates. In baseline conditions (i.e., low serum without supplementation of any inflammatory cytokine), cultured murine primary ECs constitutively released Gas 6 in the conditioned medium (708 $\pm 50 \mathrm{pg} / 10^{6}$ cells/24h; $\left.N=5\right)$.

\section{ENDOTHELIAL GAS6 PROMOTES ACTIVATION OF ENDOTHELIAL CELLS}

To study the role of endothelial Gas6, we first investigated the response of cultured ECs, derived from WT and Gas6 ${ }^{-/}$mice, to TNF $\alpha$. After stimulating ECs for 24 hours with $100 \mathrm{ng} / \mathrm{ml} \mathrm{TNF} \alpha$, we analyzed the endothelial expression of the activation markers VCAM1 and ICAM-1, and the release of the inflammatory cytokines IL-1ß and IL-6. In baseline conditions (i.e. without TNF $\alpha$ ), we found no genotypic differences in the expression of the adhesion molecules (Figure $1 A, B$ ) or in the release of cytokines (ng per $10^{6}$ cells per $24 \mathrm{~h}$ : $0.6 \pm 0.1$ for IL-1ß and $1 \pm 0.1$ for IL- 6 in WT cells versus $0.5 \pm 0.03$ for IL-1ß and $0.8 \pm$ 0.05 for IL-6 in Gas6 ${ }^{-1-}$ cells; $P=N S$ ). Upon TNF $\alpha$ stimulation, WT ECs expressed elevated levels of VCAM-1 and ICAM-1 (Figure 1A,B), and released $\sim 10$-fold more IL-1 1 and IL-6 (ng per $10^{6}$ cells per 24 h: $6 \pm 1$ for IL- $1 B$ and $11 \pm 1$ for IL-6; $P<0.05$ versus control). In contrast, in the absence of Gas6, TNF $\alpha$ failed to activate ECs as evidenced by the lower levels of adhesion molecules (Figure $1 A, B$ ) and cytokine release (ng per $10^{6}$ cells per 24 h: $0.9 \pm 0.1$ for IL-1ß and $2 \pm 1$ for IL- 6 ; $P=N S$ versus control; $P<0.05$ versus WT). The defective upregulation of VCAM-1 and ICAM-1 expression in Gas6 ${ }^{-1}$ ECs was confirmed in vivo. Indeed, by immunostaining, fewer ECs in the heart expressed VCAM-1 and ICAM-1 at $24 \mathrm{~h}$ after a systemic challenge with TNF $\alpha$ in Gas6 ${ }^{-/}$than WT mice (Figure $1 C-J$ ). The increased response of WT ECs to TNF $\alpha$ was, however, not due to (removed as requested) an increased release of Gas 6 by ECs, stimulated with TNF $\alpha\left(\mathrm{pg} / 10^{6}\right.$ cells $/ 24 \mathrm{~h}: 708 \pm 50$ in baseline versus $669 \pm 58$ after TNF $\alpha ; N=5 ; P=N S$ ) (removed as requested). 
The effect of Gas 6 was not restricted to murine ECs, but Gas6 also regulated the activation of human ECs. Indeed, Gas6 was expressed in HUVECs (mRNA levels normalized for transcript levels of TATA box binding protein, or TBP: $26.1 \pm 0.3 ; N=3$ ). Knockdown with a Gas6-selective RNAi construct reduced the Gas6 expression in HUVECs by $-75 \%$ and reduced the expression of ICAM-1 in response to TNF $\alpha$, while a control plasmid (encoding a mismatched sequence) was ineffective (Figure $1 K$ ). Thus, Gas6 promotes the responsiveness of ECs to an inflammatory stimulus.

\section{AXL MEDIATES THE ENDOTHELIAL RESPONSE TO GAS6}

We also assessed which of the Gas6 receptors (Tyro-3, Axl, or Mer) on ECs mediated the response to Gas6. All three receptors were expressed in HUVECs (mRNA expression levels normalized to those of the TBP: $135 \pm 3$ for Axl, 13.4 \pm 1.0 for Mer, and $\underline{3.2 \pm 0.3 \text { for Tyro3; } N=3 \text { ). Transfection of HUVECs with siRNAs for Axl or Tyro3 efficiently }}$ reduced the expression of $\mathrm{Axl}$ and Tyro3 by $\sim 70 \%$ and $~ 80 \%$, respectively (mRNA levels normalized to those of TBP: $45 \pm 3$ for $\mathrm{Axl}$ and $0.5 \pm 0.1$ for Tyro3; $\mathrm{N}=3$ ). Knockdown of these Gas 6 receptors did not affect EC expression levels of ICAM- 1 in baseline conditions. However, the upregulation of ICAM-1 in response to TNF $\alpha$ was reduced upon knockdown of $A x \mathrm{l}$, but not of Tyro3 (Figure $1 K$ ). Unfortunately, knockdown of Mer failed to reduce the expression of Mer in HUVECs (mRNA levels normalized to those of the TBP: $11.6 \pm 1.4$; $\mathrm{N}=3$ ), precluding further analysis. Thus, binding of Gas6 to Axl is dispensible for baseline expression of ICAM-1, but necessary for the TNF $\alpha$-induced expression of ICAM-1.

\section{GAS6 PROMOTES THE SEQUESTRATION OF PLATELETS ONTO ENDOTHELIUM}

Prompted by the finding that loss or knock-down of Gas6 in ECs impaired their activation in response to inflammatory stimuli in vitro, we investigated the role of Gas6 in EC activation in vivo. One of the predominant features of inflamed endothelium is the enhanced interactions with circulating cells such as platelets and leukocytes, leading to increased tethering, rolling, firm adhesion, extravasation and tissue infiltration of leukocytes ${ }^{11,38}$. To study the role of Gas6, we first determined, by intravital videomicroscopy, the tethering, rolling and adhesion of calcein-labeled platelets onto 
mesenteric venules in WT and $\mathrm{Gas6}^{-/-}$mice ${ }^{34,39}$. In baseline conditions, only a small number of platelets sequestered onto ECs in either genotype (Figure $2 A, B$ ). To selectively activate the endothelium, venules were locally superfused with the calcium ionophore A23187. Significantly more platelets interacted with the activated endothelium in WT than Gas6 $^{-/-}$mice (Figure 2A,B), indicating that ECs, activated in the absence of Gas6, failed to efficiently sequester platelets.

We previously showed that Gas6 $^{-/-}$platelets exhibited impaired activation and aggregation ${ }^{7,10}$, but did not investigate whether they also interact less with the endothelial surface. When selectively activating the platelets (by injecting collagen together with an $\alpha_{l 1 b} \beta_{3}$ antagonist to avoid aggregation), tethering, rolling and adhesion of platelets on ECs in vivo was impaired in the absence of Gas6 (Figure $2 A, B$ ). Importantly, endothelial sequestration of single platelets was also impaired in $\mathrm{Gas}^{-/-}$mice when both platelets and endothelium were activated (Figure $2 A, B$ ). Thus, Gas6 promotes the sequestration of circulating platelets onto activated ECs in vivo.

\section{GAS6 PROMOTES LEUKOCYTE SEQUESTRATION ON ENDOTHELIUM}

To study the role of Gas6 in the sequestration of leukocytes on ECs, we also determined, by intravital videomicroscopy, the interactions of circulating leukocytes with the mesenteric endothelium, using another labeling protocol (in vivo labeling via rhodamin$\mathrm{G}$ infusion ${ }^{40,41}$ ). Since leukocytes progressively sequester onto the activated endothelium ${ }^{34}$, we analyzed both the number of sequestered leukocytes, as well as the kinetics of their sequestration in response to $\mathrm{A} 23187$. In baseline conditions, only a small number of leukocytes interacted with the mesenteric endothelium in either genotype (Figure 2C). When the endothelium was selectively activated by topical A23187 administration, leukocyte sequestration progressively increased in WT mice, reaching a plateau phase at 20 minutes after activation (Figure 2C). In contrast, in Gas6 ${ }^{-/-}$mice, leukocyte sequestration was not only delayed but, in addition, significantly fewer leukocytes interacted with the activated endothelium at all time points in the absence of Gas6 (Figure 
2C). Taken together, Gas6 amplifies and accelerates the sequestration of circulating leukocytes onto activated ECs.

\section{P-selectin, A DOWNSTREAM MEDiator of GAs6?}

P-selectin promotes the rapid sequestration of leukocytes and platelets on ECs, early after their activation ${ }^{34,38,41-45}$. We therefore reasoned that the defective sequestration of circulating cells on activated ECs in Gas6 ${ }^{-/-}$mice might be attributable to an impaired upregulation of P-selectin on these cells. In view of the lack of high-quality antibodies to reliably and reproducibly detect P-selectin expression on endothelium, we resorted to a functional characterization of the role of P-selectin in vivo. If the activity of Gas6 would rely, at least in part, on upregulation of P-selectin, then P-selectin inhibitors would be expected to reduce the sequestration of circulating cells on ECs in WT but not in Gas6 $6^{-/-}$ mice. To neutralize P-selectin in vivo, we used gallic acid (GA), a well-known polyphenol acting as a selective antagonist of P-selectin, but not of E-selectin ${ }^{34,35,46}$. As expected (since P-selectin is poorly expressed on quiescent ECs), GA did not alter the interactions of leukocytes with resting endothelium in either genotype (Figure 2D). However, when the endothelium was selectively activated by topical administration of A23187, GA inhibited the interactions of leukocytes with ECs in WT mice, notably, to the same level as in Gas6 $6^{-1-}$ mice, while GA was ineffective in Gas6 ${ }^{-/}$mice (Figure 2D). Similar effects were observed when studying the effect of GA on the sequestration of platelets on ECs (Figure $2 E$ ). Thus, P-selectin is a likely downstream mediator of Gas6 in promoting the sequestration of leukocytes and platelets on activated ECs.

To further underscore that Gas6 indeed induced the surface expression of Pselectin, we analyzed whether Gas6 affected the secretion of other factors, known to be co-released with P-selectin. The hemostatic protein von Willebrand Factor (VWF) is such a molecule, stored together with P-selectin in endothelial Weibel-Palade bodies and coreleased from these stores upon EC activation ${ }^{38,47,48}$. Videomicroscopy revealed that EC activation by A23187 in WT mice exposed VWF on the luminal surface of ECs, visualized 
as 'platelet strings' sequestered onto VWF multimers ${ }^{39}$. In contrast, in Gas6 $6^{-/-}$mice, fewer platelet strings were detected and only at later time points (Figure $2 F$ ). The reduced VWFplatelet strings in $\mathrm{Gas6}^{-/-}$mice were not attributable to an impaired capacity of $\mathrm{Gas6}^{-/-}$ platelets to bind VWF (not shown), or to a reduced number of Weibel-Palade bodies in Gas6 $^{-/}$ECs (total volume of Weibel-Palade bodies per image stack in computed voxels:

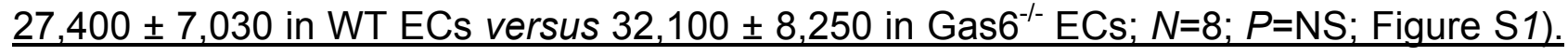
Together, these findings suggest that, in the absence of Gas6, endothelial degranulation upon EC activation with A23187 is impaired.

\section{GAS6 PROMOTES THE SEQUESTRATION OF PLATELET-LEUKOCYTE-CONJUGATES}

Recent reports indicate that platelets play a pivotal role in the sequestration of leukocytes on ECs in a P-selectin-dependent manner ${ }^{11,45}$. Indeed, through P-selectin, platelets bind to the P-selectin ligand PSGL on leukocytes, and thereby form multicellular conjugates, which allows them to release cytokines to further activate the leukocytes ${ }^{11,49}$. These conjugates of P-selectin ${ }^{+}$platelets / $\mathrm{PSGL}^{+}$leukocytes tether and roll on ECs, with a higher avidity than unconjugated leukocytes, thereby enhancing endothelial inflammation 42,44. In addition, the P-selectin mediated leukocyte activation, which results from leukocyte conjugation with platelets, further promotes leukocyte sequestration to the endothelium and subsequent extravasation, overall leading to an amplified inflammatory response 41,43,46. We previously showed that P-selectin levels on activated platelets were reduced in the absence of Gas6 ${ }^{7}$. Here, we analyzed, by flow cytometry, the formation of heteroconjugates, consisting of CD41/61+ platelets and CD45 granulocytes in WT and $\mathrm{Gas6}^{-/}$mice. Comparable amounts of conjugates were present in baseline conditions in both genotypes (\% of total number of granulocytes: $1.2 \pm 0.2 \%$ in $\mathrm{Gas6}^{-/-}$mice versus 1.3 $\pm 0.4 \%$ in WT mice; $N=5 ; P=N S$ ). However, after administration of LPS (40 mg/kg i.p.), fewer conjugates formed in Gas6 ${ }^{-/-}$than WT animals $\left(3.0 \pm 0.4 \%\right.$ in Gas6 ${ }^{-/-}$mice versus 4.7 $\pm 0.6 \%$ in WT mice; $N=5 ; P<0.05$ ). A similar 4 -fold increase in heteroconjugate formation was recently shown to substantially activate circulating monocytes ${ }^{46}$.

By videomicroscopy, we also found that loss of Gas6 impaired the formation and the tethering / rolling of these conjugates onto the endothelium. In baseline conditions, no 
genotypic differences were found in the number of conjugates visualized per min in the mouse mesenteric circulation ( $3 \pm 1$ in WT mice versus $2 \pm 1$ in Gas6 ${ }^{-/}$mice; $N=10-16$; $P=\mathrm{NS}$ ), and none of them tethered / rolled. Upon selective activation of platelets (see above), fewer conjugates were visualized in $\mathrm{Gas6}^{-/-}$mice (conjugates observed per min: $32 \pm 9$ in WT mice versus $5 \pm 2$ in $\mathrm{Gas6}^{-/}$mice; $\left.N=10-14 ; P<0.05\right)$. Correspondingly, conjugates interacted more with the endothelium in WT than Gas6 ${ }^{-/}$mice (conjugates tethering / rolling per min: $5 \pm 2$ in WT mice versus $2 \pm 1$ in Gas6 $6^{-/}$mice; $N=10-14$; $P<0.05)$. After activation of both platelets and ECs, fewer conjugates formed and tethered / rolled onto the endothelium in Gas6 ${ }^{-1-}$ mice (conjugates observed per min: $36 \pm 6$ in WT mice versus $4 \pm 1$ in Gas6 ${ }^{-/}$mice; conjugates tethering / rolling per min: $17 \pm 5$ in WT mice versus $1 \pm 1$ in Gas6 $^{-/}$mice; $\left.N=12-15 ; P<0.05\right)$. Thus, Gas6 promotes both, the formation and endothelial sequestration of platelet-leukocyte conjugates, likely by regulating the expression levels of platelet and endothelial P-selectin. Overall, Gas6 participates in the inflammatory response between ECs, platelets and leukocytes, by regulating the release of tethering and adhesion receptors in these cells.

\section{GAS6 PROMOTES LEUKOCYTE EXTRAVASATION DURING INFLAMMATION}

The above mentioned findings suggested that Gas 6 might play a role in augmenting the inflammatory response in vivo. In order to further underscore this hypothesis experimentally, we exposed $\mathrm{Gas}^{-/}$mice to a panel of inflammatory challenges in vivo, including endotoxinemia, vasculitis and heterotopic heart transplantation. To characterize leukocyte infiltration in inflamed tissue, we systemically injected LPS, a model of endotoxinemia, in WT and $\mathrm{Gas6}^{-{ }^{-}}$mice. As expected, within 4 hours after intraperitoneal injection of $20 \mathrm{mg} / \mathrm{kg}$ LPS, pulmonary myeloperoxidase activity levels - a measure of infiltrated leukocytes - increased in WT mice (absorbance units/mg tissue: $11 \pm 2$ after saline versus $23 \pm 3$ after LPS; $N=7-12 ; P<0.05)$. In contrast, in Gas $6^{-/}$mice, pulmonary myeloperoxidase levels failed to increase at all (absorbance units/mg tissue: $8 \pm 3$ after saline versus $10 \pm 2$ after LPS; $N=5-8 ; P=N S$ ), suggesting that extravasation of inflammatory cells was impaired in $\mathrm{Gas6}^{-1-}$ mice. CD45 immunostaining confirmed that fewer $\mathrm{CD} 45^{+}$leukocytes extravasated in the lungs of $\mathrm{Gas}^{-/-}$than WT animals (Figure 
$3 A, B)$. Thus, Gas6 is required for leukocyte extravasation in conditions of systemic inflammation.

\section{GAS6 PROMOTES VASCULITIS}

We also injected LPS in the footpad of mice to induce localized vasculitis and thrombosis ("Schwartzman reaction"). Injection of $50 \mu \mathrm{g}$ of LPS (in $20 \mu \mathrm{l}$ saline) in the footpad caused redness, swelling and temperature elevation of the footpad in both genotypes. However, semi-quantitative scoring of redness and swelling revealed that, compared to WT mice, these symptoms were less severe in Gas6 $6^{-1-}$ mice. Indeed, when scoring the redness on a scale from 0-3 (ranging from 'no redness' to 'light red' over 'dark red' to 'gangrene'), a significant genotypic difference was found after injection of $50 \mu \mathrm{g}$ of LPS (redness score: $2.4 \pm 0.2$ in WT mice versus $1.6 \pm 0.2$ in Gas6 $6^{-1}$ animals; $N=6$; $P<0.05)$. Histological analysis showed that fewer leukocytes accumulated in the adventitia of vessels in Gas6 $^{-/-}$mice (CD45 ${ }^{+}$cells, \% of all cells per microscopic field: $68 \pm 5 \%$ in WT mice versus $10 \pm 4 \%$ in Gas6 $^{-1-}$ mice; $N=6 ; P<0.05$, Figure $\left.3 C, D\right)$, suggesting that loss of Gas6 attenuated the severity of vasculitis. In addition, fewer leukocytes infiltrated the inflamed muscle in Gas6 $^{-/}$mice (CD45 ${ }^{+}$cells, $\%$ of all cells per microscopic field: $51 \pm 12 \%$ in WT mice versus $29 \pm 15 \%$ in Gas $6^{-1-}$ mice; $N=6 ; P<0.05$, Figure $\left.3 C, D\right)$. Hence, loss of Gas6 impaired leukocyte extravasation in conditions of local inflammation.

Venous thrombosis during vasculitis was also reduced in $\mathrm{Gas6}^{-/}$mice. Indeed, injection of $50 \mu \mathrm{g}$ LPS caused venous thrombosis in $88 \%$ of veins in WT mice, but only in $44 \%$ of veins in Gas6 $^{-/}$mice $(P<0.05$; Figure $3 E, F)$. Arteries characteristically contained fewer thrombi; injection of $50 \mu \mathrm{g}$ LPS caused arterial thrombosis in 10\% of arteries in WT mice but in none of the arteries in Gas6 ${ }^{-/}$mice. Hence, the impaired vascular inflammation in $\mathrm{Gas6}^{-/-}$mice was accompanied by a reduced incidence of venous thrombosis.

\section{GAS6 ACCELERATES GRAFT DESTRUCTION OF TRANSPLANTED HEARTS}

In an established mouse model of heterotopic heart transplantation ${ }^{50}$, acute graft destruction, as a consequence of an extended warm transplant ischemia time, is primarily triggered by an intense inflammatory cell infiltration ${ }^{51}$. WT or Gas $6^{-/}$mouse donor hearts 
were grafted in syngeneic WT or Gas6 $^{-/}$recipients, respectively, and beating of the transplanted hearts was followed daily in order to determine graft destruction. Upon grafting of WT hearts into WT recipients, 10 of the 11 grafts stopped beating within 7 to 12 days due to profound inflammatory cell infiltration, and myocarditis, resulting in cardiomyocyte necrosis (Figure $4 A, C, E$ ). VWF immunostaining in combination with a nuclear counterstaining revealed that platelets, leukocytes and platelet / leukocyte conjugates often adhered to the wall of the coronary vessels in the graft (Figure 4G,H).

By contrast, when $\mathrm{Gas}^{-/}$hearts were grafted in $\mathrm{Gas6}^{-/-}$recipients, all 9 grafts survived for $>60$ days, and appeared normal without signs of myocardial cell death, inflammation, or platelet / leukocyte sequestration $(P<0.05$ versus WT in WT; Figure $4 B, D, F, I)$. Consistent with our in vitro results (see above), immunostaining confirmed that the expression of VCAM-1 and ICAM-1 by ECs was less prominent in Gas6 $^{-/-}$grafts compared to WT grafts (Figure $4 J-M$ ). Thus, loss of Gas6 delays graft destruction by attenuating tissue inflammation.

To study the relative importance of Gas 6 production by the graft or recipient, we performed additional genetic cross-over experiments. When Gas ${ }^{-/-}$hearts were grafted into WT recipients, $70 \%$ of the grafts stopped beating within 7 to 12 days $(N=6 ; P<0.05$ versus $\mathrm{Gas6}^{-/}$in $\mathrm{Gas6}^{-/}$), with histological signs of inflammation and myocardial cell death. Similar results were obtained when WT hearts were grafted in Gas6 $6^{--}$recipients $(N=6$; $P<0.05$ versus Gas6 $^{-/}$in $\mathrm{Gas6}^{-1}$ ). These data suggest that Gas6 produced by both, the donor heart (presumably produced by ECs) and host tissue (released by platelets or circulating in the plasma), determine graft destruction. 


\section{DISCUSSION}

This study provides novel evidence that Gas6 promotes EC activation and participates in the interactions between ECs, platelets and leukocytes during inflammation. The principal findings of this study are: (i) Gas6 amplifies EC activation in response to inflammatory stimuli; (ii) Gas6 promotes and accelerates the sequestration of circulating platelets and leukocytes, in a P-selectin-dependent fashion; (iii) Gas6 also promotes the formation and endothelial sequestration of circulating platelet-leukocyte conjugates; and (iv) Gas6 promotes leukocyte extravasation, inflammation and thrombosis in mouse models of endotoxinemia, vasculitis and heart transplantation. Thus, these findings highlight a pivotal role for Gas6 in enhancing interactions between ECs and circulating cells during inflammation.

Our findings indicate that Gas6 promotes EC activation in response to the inflammatory stimuli TNF $\alpha$ or LPS. Indeed, in response to TNF $\alpha$, loss or knockdown of Gas6 attenuates endothelial expression of adhesion receptors and the release of proinflammatory cytokines by both mouse and human ECs in vitro. Moreover, the impaired recruitment of circulating cells onto $\mathrm{Gas6}^{-/-}$ECs in vivo was likely attributable to absent expression of Gas6 by ECs, since leukocyte recruitment was impaired when ECs in Gas6 ${ }^{-}$ I- mice were selectively activated.

The reduced activation of cultured $\mathrm{Gas}^{-/-}$ECs translated in an impaired and delayed sequestration of circulating cells onto activated endothelium in the absence of Gas6 in vivo. Since loss of Gas6 reduced the recruitment of platelets, leukocytes and platelet-leukocyte conjugates, we reasoned that the culprit might be reduced levels of $\mathrm{P}$ selectin, an endothelial receptor, involved in the sequestration of these cells ${ }^{38,42,43}$. Indeed, by intravital videomicroscopy and using a P-selectin inhibitor, we found that, upon selective activation of the endothelium, Gas 6 promotes and catalyzes the sequestration of circulating leukocytes and platelets in a P-selectin-dependent manner. Interestingly, gallic acid failed to suppress the sequestration of platelets and leukocytes on $\mathrm{Gas}^{-/-}$ endothelium. Since ECs upregulate their cell surface levels of P-selectin through rapid translocation of Weibel-Palade bodies, in which P-selectin and other molecules are stored 47 , these findings suggest that release of P-selectin from these intracellular stores was 
impaired. Further support that loss of Gas6 impaired the exocytosis process of WeibelPalade bodies was provided by our findings that the functional release of VWF (another molecule stored in Weibel-Palade bodies) was also defective in Gas6 ${ }^{-1-}$ mice, while the number of endothelial Weibel-Palade bodies was normal.

Apart from regulating the levels of endothelial P-selectin, Gas6 also regulated the expression of various other endothelial molecules. Indeed, in the absence of Gas6, activated ECs failed to upregulate the expression of adhesion molecules (VCAM-1, ICAM1) and the release of cytokines involved in the recruitment of leukocytes (IL-1ß, IL-6). This in vitro finding translated in a reduction of leukocyte extravasation in $\mathrm{Gas}^{-{ }^{-}}$mice in vivo, in models of heart transplantation, endotoxinemia and vasculitis. Indeed, histological analysis of the transplanted hearts revealed that loss of Gas6 prevented the development of myocarditis and leukocyte infiltration in the grafts, consistent with previous reports on the role of Gas6 in graft rejection ${ }^{52,53}$. In graft myocarditis and destruction, endothelial Gas6 plays a dominant role, as $70 \%$ of the cardiac grafts were rejected when Gas6 $6^{-1-}$ recipient mice received WT donor hearts, and careful high magnification microscopic analysis of the WT grafts revealed that platelets, leukocytes and platelet-leukocyte conjugates often adhered to the wall of the coronary vessels. In addition, in the absence of Gas6, leukocyte extravasation was reduced after local and systemic administration of LPS. During endotoxinemia, loss of Gas6 also impaired the formation of platelet-leukocyte conjugates, which might have contributed to the reduced leukocyte extravasation and activation ${ }^{11,34,49}$. Obviously, our findings do not exclude the possibility that Gas 6 also affects leukocytes directly. Previous reports indeed showed that Gas6 and its receptors exert both positive and negative effects on leukocyte activation ${ }^{14,27,28,31}$.

Platelet Gas6 probably also plays a role in orchestrating inflammation, because of its role in regulating the expression of platelet P-selectin. Indeed, previous reports showed that, in atherosclerosis and other inflammatory conditions, platelet P-selectin accelerates the extravasation of leukocytes into the inflamed tissue via the formation of plateletleukocyte conjugates, thereby enabling binding of leukocytes to endothelial PSGL-1 or other sialoglycoproteins $34,41,42,44$. P-selectin, expressed by activated and sequestered platelets, not only activates circulating leukocytes, but can also increase EC activation and 
the levels of endothelial P-selectin ${ }^{45}$. We found that, after systemic injection of LPS, the formation of platelet-leukocyte conjugates was impaired in $\mathrm{Gas6}^{-/-}$mice, which extends our previous report on reduced P-selectin levels in $\mathrm{Gas6}^{-/-}$platelets after activation ${ }^{7}$. In addition, loss of Gas6 impaired the endothelial sequestration of platelets, leukocytes and their conjugates, which likely contributed to the reduction of graft myocarditis and destruction in the heart transplantation model (in case Gas6 $^{-/}$grafts were used). Thus, Gas6 regulates platelet activation, the levels of platelet P-selectin and subsequent interactions with leukocytes and ECs during inflammation.

An outstanding question is how Gas6 acts at the molecular level. ECs release Gas6 constitutively, but binding of Gas6 to AxI is redundant for regulating ICAM-1 expression in baseline conditions. Upon activation by TNF $\alpha, E C s$ do not produce increased amounts of Gas6, but respond to Gas6 (a process, requiring the presence of Axl), possibly suggesting that Gas6 is only able to bind to Axl on activated ECs. An intriguing possibility is that the altered lipid composition of the plasma membrane in such conditions would favour an interaction of Gas6, via its gamma-carboxylated Gla-domain, to negatively charged phospholipids on activated EC surfaces, thereby increasing the affinity of Gas6 for its receptor ${ }^{20}$. We can also not exclude the (hypothetical) possibility that Gas6 may, in addition to its extracellular activity, also act via "intracrine" mechanisms, as recently documented for VEGF ${ }^{54}$. Obviously, future studies will be required to elucidate the precise molecular mechanism of Gas6.

Our findings might also have some medical implications. Expression analyses in the mouse indicate that ECs, platelets, and leukocytes produce and release Gas6, but Gas6 levels in human platelets are variable, from negligible ${ }^{37}$ to substantial ${ }^{7}$. We show here that Gas6 also determines the response of human ECs to TNF $\alpha$ in vitro. Interestingly, Gas6 plasma levels are increased in endotoxinemic mice and septic patients (unpublished and ${ }^{29,30}$ ). Besides being a biomarker of disease severity ${ }^{29,30}$, it remains to be investigated whether the elevated plasma levels of Gas6 in response to sepsis are functionally relevant. Since treatment with activated protein $C$, the only available drug for sepsis, primarily protects the endothelium ${ }^{55,56}$, our findings on the role of Gas 6 in augmenting platelet-EC-leukocyte interactions and their activation profiles suggest that inhibition of 
Gas6 might warrant further consideration as a novel strategy for the treatment of sepsis or transplantation-induced organ rejection. 


\section{ACKNOWLEDGEMENTS}

The technical assistance of A. Bouché, K. Brepoels, P. Chevron, N. Dai, M. De Mol, M. Deprez, B. Hermans, A. Janssen, S. Jansen, A. Manderveld, L. Notebaert, J. Souffreau, S. Terclavers, A. Vandenhoeck, P. Vandervoort, B. Vanwetswinkel, E. Weltens, S. Wyns (Leuven) and I. Nilsson (Malmo) is gratefully acknowledged. This work was supported in part by the Swedish Research Council (\#07143), by the Spanish Ministry of Science and Technology (grants SAF2004-07539-C02 and BES2003-0230), by a grant from the Swiss National Foundation for Scientific research (\#PPOOB-106690/1), by a grant from the Belgian FWO (\#G0265.01), by grant \#GOA2004/09 from the Concerted Research Activities, Belgium and by an unrestricted Bristol-Myers-Squibb grant to P.C. E.L. is a postdoctoral fellow of the Dr. E. Dekker Program of the Dutch Heart Foundation (\#2000T041), M.A. is a post-doctoral fellow of the Philip Morris External Research Program and M.T. is a post-doctoral research fellow of the Belgian IWT. 


\section{REFERENCES}

1. Hafizi S, Dahlback B. Gas6 and protein S. Vitamin K-dependent ligands for the Axl receptor tyrosine kinase subfamily. Febs J. 2006;273:5231-5244.

2. Stitt TN, Conn G, Gore M, et al. The anticoagulation factor protein S and its relative, Gas6, are ligands for the Tyro 3/Axl family of receptor tyrosine kinases. Cell. 1995;80:661-670.

3. Godowski PJ, Mark MR, Chen J, Sadick MD, Raab H, Hammonds RG. Reevaluation of the roles of protein $S$ and Gas6 as ligands for the receptor tyrosine kinase Rse/Tyro 3. Cell. 1995;82:355-358.

4. Manfioletti G, Brancolini C, Avanzi G, Schneider C. The protein encoded by a growth arrestspecific gene (gas6) is a new member of the vitamin K-dependent proteins related to protein $S$, a negative coregulator in the blood coagulation cascade. Mol Cell Biol. 1993;13:4976-4985.

5. Nakano T, Higashino K, Kikuchi N, et al. Vascular smooth muscle cell-derived, Gla-containing growth-potentiating factor for $\mathrm{Ca}(2+)$-mobilizing growth factors. J Biol Chem. 1995;270:57025705.

6. Avanzi GC, Gallicchio M, Cavalloni G, et al. GAS6, the ligand of Axl and Rse receptors, is expressed in hematopoietic tissue but lacks mitogenic activity. Exp Hematol. 1997;25:12191226.

7. Angelillo-Scherrer A, García de Frutos P, Aparicio C, et al. Deficiency or inhibition of Gas6 causes platelet dysfunction and protects mice against thrombosis. Nat Med. 2001;7:215-221.

8. Chen C, Li Q, Darrow AL, et al. Mer receptor tyrosine kinase signaling participates in platelet function. Arterioscler Thromb Vasc Biol. 2004;24:1118-1123.

9. Gould WR, Baxi SM, Schroeder R, et al. Gas6 receptors Axl, Sky and Mer enhance platelet activation and regulate thrombotic responses. J Thromb Haemost. 2005;3:733-741.

10. Angelillo-Scherrer A, Burnier L, Flores N, et al. Role of Gas6 receptors in platelet signaling during thrombus stabilization and implications for antithrombotic therapy. J Clin Invest. 2005;115:237-246.

11. Wagner DD, Burger PC. Platelets in inflammation and thrombosis. Arterioscler Thromb Vasc Biol. 2003;23:2131-2137.

12. Melaragno MG, Wuthrich DA, Poppa $V$, et al. Increased expression of Axl tyrosine kinase after vascular injury and regulation by $G$ protein-coupled receptor agonists in rats. Circ Res. 1998;83:697-704.

13. O'Donnell K, Harkes IC, Dougherty L, Wicks IP. Expression of receptor tyrosine kinase AxI and its ligand Gas6 in rheumatoid arthritis: evidence for a novel endothelial cell survival pathway. Am J Pathol. 1999;154:1171-1180.

14. Camenisch T, Koller B, Earp H, Matsushima GK. A novel receptor tyrosine kinase, Mer, inhibits TNF-alpha production and lipopolysaccharide-induced endotoxic shock. J Immunol. 1999;162:3498-3503.

15. Fiebeler A, Park JK, Muller DN, et al. Growth arrest specific protein 6/Axl signaling in human inflammatory renal diseases. Am J Kidney Dis. 2004;43:286-295.

16. Konishi A, Aizawa T, Mohan A, Korshunov VA, Berk BC. Hydrogen peroxide activates the gas6-axl pathway in vascular smooth muscle cells. J Biol Chem. 2004;279:28766-28770.

17. D'Arcangelo D, Gaetano C, Capogrossi MC. Acidification prevents endothelial cell apoptosis by Axl activation. Circ Res. 2002;91:e4-12.

18. Healy AM, Schwartz JJ, Zhu X, Herrick BE, Varnum B, Farber HW. Gas 6 promotes Axlmediated survival in pulmonary endothelial cells. Am J Physiol Lung Cell Mol Physiol. 2001;280:L1273-1281.

19. Hasanbasic I, Cuerquis J, Varnum B, Blostein MD. Intracellular signalling pathways involved in gas6-Axl mediated survival of endothelial cells. Am J Physiol Heart Circ Physiol. 2004;287:H1207-H1213.

20. Hasanbasic I, Rajotte I, Blostein M. The role of gamma-carboxylation in the anti-apoptotic function of gas6. J Thromb Haemost. 2005;3:2790-2797. 
21. Bellosta $P$, Costa M, Lin DA, Basilico $C$. The receptor tyrosine kinase ARK mediates cell aggregation by homophilic binding. Mol Cell Biol. 1995;15:614-625.

22. McCloskey P, Fridell YW, Attar E, et al. GAS6 mediates adhesion of cells expressing the receptor tyrosine kinase Axl. J-Biol-Chem. 1997;272:23285-23291.

23. Heiring $C$, Dahlback B, Muller YA. Ligand recognition and homophilic interactions in Tyro3: structural insights into the Axl/Tyro3 receptor tyrosine kinase family. J Biol Chem. 2004;279:6952-6958.

24. Gallicchio M, Mitola S, Valdembri D, et al. Inhibition of vascular endothelial growth factor receptor 2-mediated endothelial cell activation by Axl tyrosine kinase receptor. Blood. 2005;105:1970-1976.

25. Behrens EM, Gadue P, Gong SY, Garrett S, Stein PL, Cohen PL. The mer receptor tyrosine kinase: expression and function suggest a role in innate immunity. Eur $\mathrm{J}$ Immunol. 2003;33:2160-2167.

26. Scott RS, McMahon EJ, Pop SM, et al. Phagocytosis and clearance of apoptotic cells is mediated by MER. Nature. 2001;411:207-211.

27. Lu Q, Lemke G. Homeostatic regulation of the immune system by receptor tyrosine kinases of the Tyro 3 family. Science. 2001;293:306-311.

28. Lemke G, Lu Q. Macrophage regulation by Tyro 3 family receptors. Curr Opin Immunol. 2003;15:31-36.

29. Borgel D, Clauser S, Bornstain C, et al. Elevated growth-arrest-specific protein 6 plasma levels in patients with severe sepsis. Crit Care Med. 2006;34:219-222.

30. Gibot S, Massin F, Cravoisy A, et al. Growth arrest-specific protein 6 plasma concentrations during septic shock. Crit Care. 2007;11:R8.

31. Avanzi GC, Gallicchio M, Bottarel F, et al. GAS6 inhibits granulocyte adhesion to endothelial cells. Blood. 1998;91:2334-2340.

32. Carmeliet $P$, Moons $L$, Luttun $A$, et al. Synergism between vascular endothelial growth factor and placental growth factor contributes to angiogenesis and plasma extravasation in pathological conditions. Nat Med. 2001;7:575-583.

33. Herbert JM, Lale A, Pereillo JM, Derocq JM, Casellas P. Echinomycin suppresses the pyrogenic effects of endotoxin and interleukin-1 beta in human endothelial cells and peripheral blood mononuclear cells. Thromb Haemost. 1996;75:359-362.

34. Appeldoorn CC, Bonnefoy A, Lutters BC, et al. Gallic acid antagonizes P-selectin-mediated platelet-leukocyte interactions: implications for the French paradox. Circulation. 2005;111:106112.

35. Appeldoorn CC, Molenaar TJ, Bonnefoy A, et al. Rational optimization of a short human Pselectin-binding peptide leads to nanomolar affinity antagonists. J Biol Chem. 2003;278:10201-10207.

36. Burnier L, Borgel D, Angelillo-Scherrer A, Fontana P. Plasma levels of the growth arrestspecific gene 6 product (Gas6) and antiplatelet drug responsiveness in healthy subjects. J Thromb Haemost. 2006;4:2283-2284.

37. Balogh I, Hafizi S, Stenhoff J, Hansson K, Dahlback B. Analysis of Gas6 in human platelets and plasma. Arterioscler Thromb Vasc Biol. 2005;25:1280-1286.

38. Wagner DD. New links between inflammation and thrombosis. Arterioscler Thromb Vasc Biol. 2005;25:1321-1324.

39. Bonnefoy A, Daenens K, Feys HB, et al. Thrombospondin-1 controls vascular platelet recruitment and thrombus adherence in mice by protecting (sub)endothelial VWF from cleavage by ADAMTS13. Blood. 2006;107:955-964.

40. Massberg S, Eisenmenger S, Enders G, Krombach F, Messmer K. Quantitative analysis of small intestinal microcirculation in the mouse. Res Exp Med (Berl). 1998;198:23-35.

41. Huo $\mathrm{Y}$, Schober A, Forlow SB, et al. Circulating activated platelets exacerbate atherosclerosis in mice deficient in apolipoprotein E. Nat Med. 2003;9:61-67.

42. Theilmeier G, Lenaerts T, Remacle C, Collen D, Vermylen J, Hoylaerts MF. Circulating activated platelets assist THP-1 monocytoid/endothelial cell interaction under shear stress. Blood. 1999;94:2725-2734. 
43. Burger PC, Wagner DD. Platelet P-selectin facilitates atherosclerotic lesion development. Blood. 2003;101:2661-2666.

44. da Costa Martins P, Garcia-Vallejo JJ, van Thienen JV, et al. P-Selectin Glycoprotein Ligand-1 Is Expressed on Endothelial Cells and Mediates Monocyte Adhesion to Activated Endothelium. Arterioscler Thromb Vasc Biol. 2007;27:1023-1029.

45. Dole VS, Bergmeier W, Mitchell HA, Eichenberger SC, Wagner DD. Activated platelets induce Weibel-Palade-body secretion and leukocyte rolling in vivo: role of P-selectin. Blood. 2005;106:2334-2339.

46. Nemmar A, Hoet PH, Vandervoort P, Dinsdale D, Nemery B, Hoylaerts MF. Enhanced peripheral thrombogenicity after lung inflammation is mediated by platelet-leukocyte activation: role of P-selectin. J Thromb Haemost. 2007; 5: 1217-1226.

47. Wagner DD. The Weibel-Palade body: the storage granule for von Willebrand factor and Pselectin. Thromb Haemost. 1993;70:105-110.

48. van Mourik JA, Romani de Wit T, Voorberg J. Biogenesis and exocytosis of Weibel-Palade bodies. Histochem Cell Biol. 2002;117:113-122.

49. Pitchford SC, Momi S, Giannini S, et al. Platelet P-selectin is required for pulmonary eosinophil and lymphocyte recruitment in a murine model of allergic inflammation. Blood. 2005;105:2074-2081.

50. Lin Y, Goebels J, Xia G, Ji P, Vandeputte M, Waer M. Induction of specific transplantation tolerance across xenogeneic barriers in the T-independent immune compartment. Nat Med. 1998;4:173-180.

51. Hu Y, Zou Y, Hala M, Dietrich H, Wick G, Xu Q. Prolonged survival of heart allografts from p53-deficient mice. Transplantation. 2000;69:2634-2640.

52. Yin JL, Pilmore HL, Yan YQ, et al. Expression of growth arrest-specific gene 6 and its receptors in a rat model of chronic renal transplant rejection. Transplantation. 2002;73:657660.

53. Yin JL, Hambly BD, Bao SS, Painter D, Bishop GA, Eris JM. Expression of growth arrestspecific gene 6 and its receptors in dysfunctional human renal allografts. Transpl Int. 2003;16:681-688.

54. Lee S, Chen TT, Barber CL, et al. Autocrine VEGF Signaling Is Required for Vascular Homeostasis. Cell. 2007;130:691-703.

55. Bernard GR, Vincent JL, Laterre PF, et al. Efficacy and safety of recombinant human activated protein C for severe sepsis. N Engl J Med. 2001;344:699-709.

56. Taylor FB, Kinasewitz G. Activated protein C in sepsis. J Thromb Haemost. 2004;2:708-717. 


\section{FIGURE LEGENDS}

\section{Figure 1: Gas6 regulates EC activation in vitro and in vivo.}

$\underline{A}, \boldsymbol{B}$, Stimulation of ECs with $100 \mathrm{ng} / \mathrm{ml}$ TNF- $\alpha$ revealed a role for Gas 6 in the activation of endothelial cells in vitro. TNF- $\alpha$ stimulates the production of VCAM-1 $(A)$ and ICAM-1 $(B)$ by WT ECs but not by Gas66-- ECs. Data represent mean \pm SEM; *: $P<0.05$ versus stimulated WT cells $(N=9)$. $C$-J, In normal heart tissue (baseline), no (VCAM-1) or limited (ICAM-1) expression of the adhesion molecules VCAM-1 $(C, D)$ and ICAM-1 $(G, H)$ can be detected in the blood vessels of either WT or $\mathrm{Gas6}^{-/}$mice. At 24 hours after intraperitoneal injection of a sublethal dose of TNF- $\alpha$, upregulated expression of VCAM-1 $(E)$ and ICAM-1 $(I)$ can be seen in the endothelial cells in WT hearts, but is absent (VCAM1 ) or reduced (ICAM-1) in Gas6 $^{-/}$hearts $(F, J)$. Magnification bar: $50 \mu \mathrm{m}$ in all panels. $\underline{\boldsymbol{K}}$, Knock-down of Gas6 or Axl in HUVECs by transfection of cells with 25 nM siRNA for respectively, Gas 6 or Axl, reduced the expression of hICAM-1 in response to TNF- $\alpha$ (10 ng/ml). In contrast, knock-down of Tyro3, using $100 \mathrm{nM}$ of Tyro3 siRNA, failed to reduce the expression of hICAM-1 on HUVECs in response to TNF- $\alpha(10 \mathrm{ng} / \mathrm{ml})$. Data represent $\%$ of the control response; $P<0.05$ versus control siRNA $(N=3)$.

Figure 2: Gas6 promotes endothelial sequestration of platelets and leukocytes via P-selectin.

$\boldsymbol{A}, \boldsymbol{B}$, In vivo videomicroscopy of mesenteric venules revealed impaired platelet-EC interactions in $\mathrm{Gas6}^{-/}$mice. Compared to WT mice, fewer platelets tethered/rolled $(A)$ and adhered $(B)$ onto the endothelial surface of the venules after single or combined activation of ECs and platelets. The endothelium was selectively activated by topical administration of A23187. Platelets were selectively activated by injection of collagen together with a GPIIb/llla antagonist to avoid aggregation. *: $P<0.05$ versus WT $(N=10-21)$. C, Loss of Gas6 delayed and impaired the sequestration of leukocytes onto the endothelium, 
activated by topical administration of A23187. $P<0.05$ versus WT (ANOVA). *: $P<0.05$ versus WT per time point $(N=10-16)$. D,E, Impaired and delayed sequestration of leukocytes $(D)$ and platelets $(E)$ onto activated endothelium in $G a s 6^{-/-}$mice can be explained by reduced P-selectin expression as P-selectin inhibition, by systemic infusion of gallic acid (GA), effectively reduced the interactions between circulating cells and the activated endothelium in WT mice but not in $\mathrm{Gas6}^{-1-}$ mice. Data were expressed as $\%$ of the maximal value in WT mice. $P<0.05$ versus WT (ANOVA; $N=7-16$ for leukocytes; $N=7$ 10 for platelets). F, Release of VWF strings was impaired and delayed in $\mathrm{Gas6}^{-{ }^{--}}$mice after topical administration of A23187. Data were expressed as $\%$ of positive vessels per time point. $P<0.05$ versus WT (ANOVA; $N=10-16$ ).

\section{Figure 3: In vivo role of Gas6 in inflammation and thrombosis.}

$A, B, \mathrm{CD} 45$ staining in lungs of $\mathrm{Gas6}^{+/+}$and $\mathrm{Gas}^{-/-}$mice 4 hours after i.p. injection of 20 $\mathrm{mg} / \mathrm{kg}$ LPS, showed higher neutrophil extravasation in the lung parenchyme of Gas6 $6^{+/+}$ mice $(A)$ compared to Gas6 $^{-/-}$animals $(B) . C, D, C D 45$ immunostaining in footpads of $\mathrm{Gas6}^{+/+}$and $\mathrm{Gas6}^{-{ }^{--}}$animals, injected with $50 \mu \mathrm{g}$ LPS, revealed extensive inflammation in the adventitial and muscle area of $\mathrm{Gas}^{+/+}$animals $(E)$, while vessels in $\mathrm{Gas6}^{-/-}$animals were less inflamed $(D) . E, F, H \& E$ staining in footpads of WT and Gas6 ${ }^{-1-}$ animals, injected with $50 \mu \mathrm{g}$ LPS, revealed the presence of large, organized thrombi covering most of the lumen in veins of $\mathrm{Gas6}^{+/+}$animals $(E)$, while vessels in $\mathrm{Gas6}^{-/}$animals contained fewer and smaller thrombi $(F)$. Magnification bar: $50 \mu \mathrm{m}$ in all panels.

Figure 4: Role of Gas6 in graft destruction of mouse heart grafts exposed to warm ischemia.

$A-F, \operatorname{H\& E}(A, D)$ and CD45 $(E, F)$ stainings of sections through WT and Gas6 $6^{-/}$mouse heart grafts, 10 days after transplantation, revealed profound inflammatory cell infiltration and myocardial cell necrosis $(A, C, E)$ in the WT heart graft. In contrast, the Gas6 ${ }^{-/}$ 
transplanted heart graft showed a remarkably normal morphology and only limited leukocyte infiltration $(B, D, F)$. G-I, Immunostaining for VWF (brown) combined with nuclear counterstaining with Harris hematoxylin (blue) revealed platelets (arrowhead in $H$ ), leukocytes and platelet-leukocyte conjugates (arrowhead in $G$ ) adhering to the wall of the coronary vessels in the graft of WT mice while this was not seen in hearts transplanted in Gas6 $^{-/}$mice (I). J-M, VCAM-1 $(J, K)$ and ICAM-1 $(L, M)$ upregulated expression is reduced in Gas6 $^{-/-}$hearts transplanted into Gas6 ${ }^{-/}$mice $(K, M)$ as compared to Gas6 ${ }^{+/+}$cardiac grafts, dissected 3 days after transplantation into $\operatorname{Gas}^{+/+}$mice $(J, L)$. Magnification bar: $100 \mu \mathrm{m}$ in panels $A, B ; 50 \mu \mathrm{m}$ in panels $C-F$ and $J-M$ and $10 \mu \mathrm{m}$ in panels $G-I$. 


\section{CONTRIBUTIONS OF THE AUTHORS}

Marc Tjwa: designed and performed experiments, analyzed data, participated in discussion and manuscript writing

Lola M. Bellido: performed experiments and analyzed data

Yuan Lin: performed experiments and analyzed data

Esther Lutgens: performed experiments and analyzed data

Stéphane Plaisance: generated research tools, performed and designed experiments, analyzed data

Françoise Bono: performed experiments and analyzed data

Nathalie Delesque-Touchard: performed experiments and analyzed data

Caroline Hervé: performed experiments and analyzed data

Rute Moura: performed experiments

An Billiau: performed experiments

Cristina Aparicio: performed experiments

Marcel Levi: performed experiments

Mat Daemen: participated in discussion

Mieke Dewerchin: designed and performed experiments, analyzed data

Florea Lupu: performed experiments and analyzed data

Jef Arnout: performed experiments and analyzed data

Mark Waer: designed experiments and participated in discussion

Jean-Marc Herbert: performed experiments, analyzed data, participated in discussion

Pablo Frutos de García: performed experiments, analyzed data, participated in discussion

Björn Dahlbäck: generated research tools, participated in discussion

Peter Carmeliet: conceived and initiated study, designed experiments, analyzed data, participated in discussion and manuscript writing; scientific direction

Marc F. Hoylaerts: designed experiments, analyzed data, participated in discussion and manuscript writing

Lieve Moons: designed experiments, analyzed data, participated in discussion and manuscript writing 

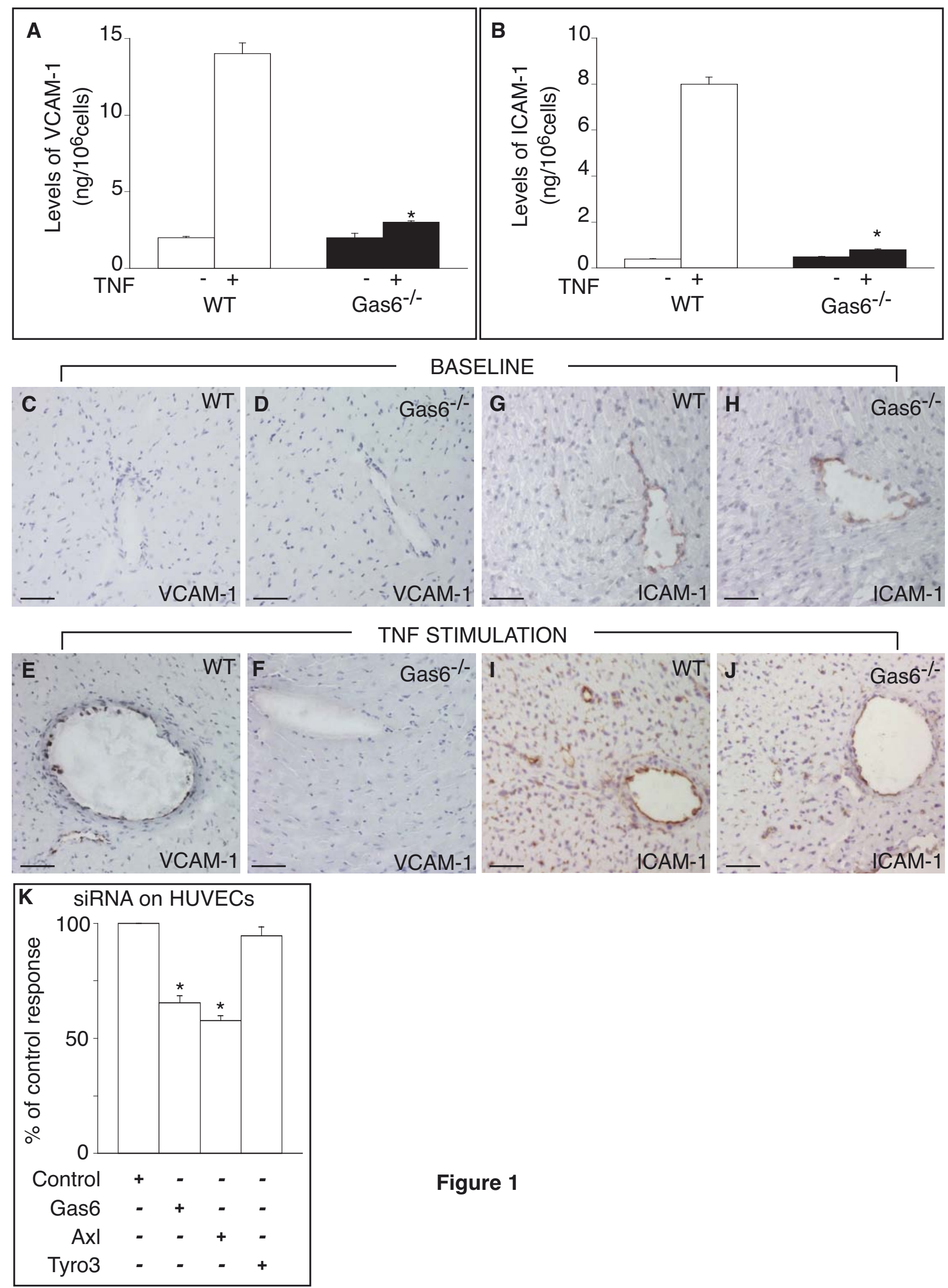

Figure 1 

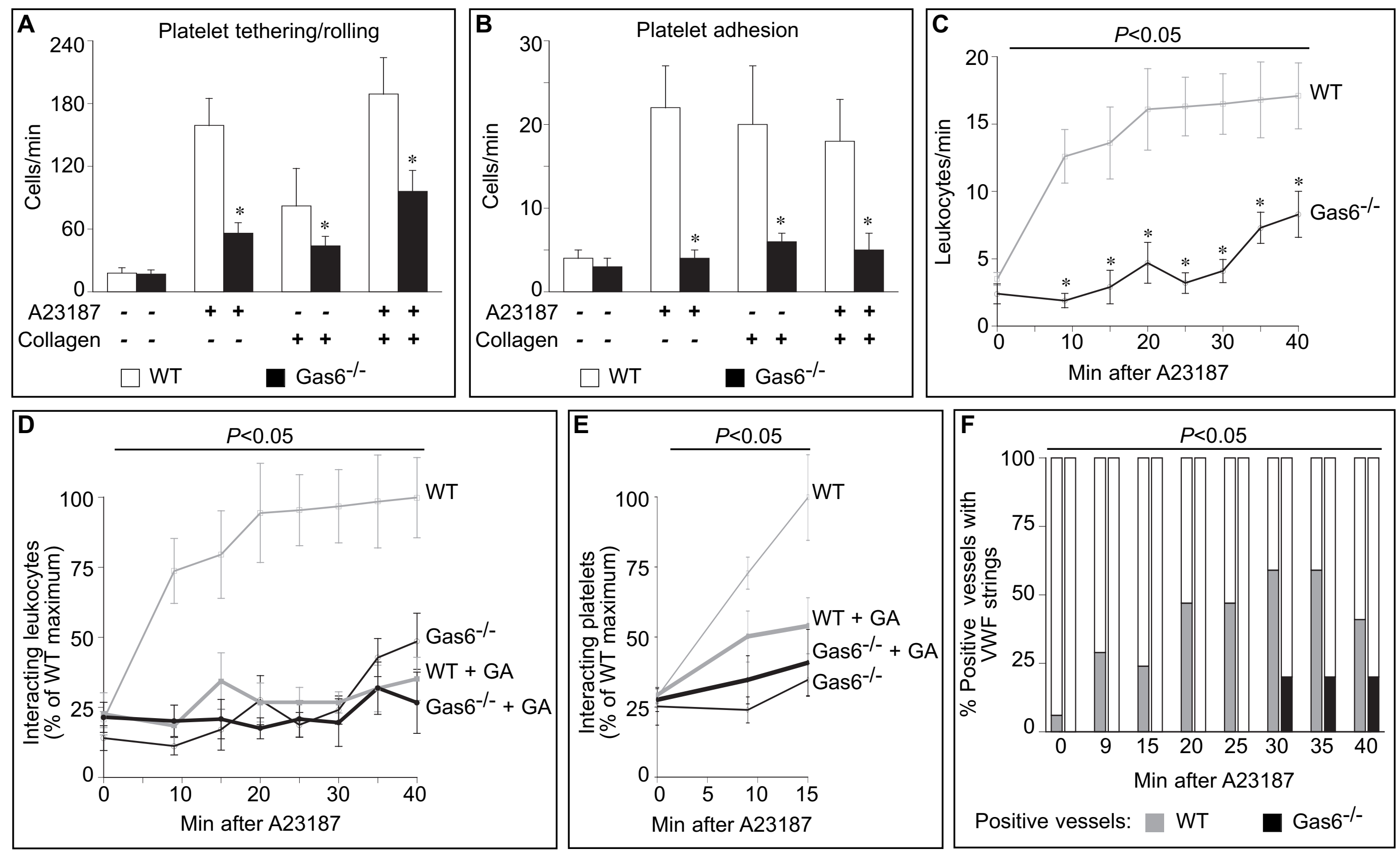

Figure 2 

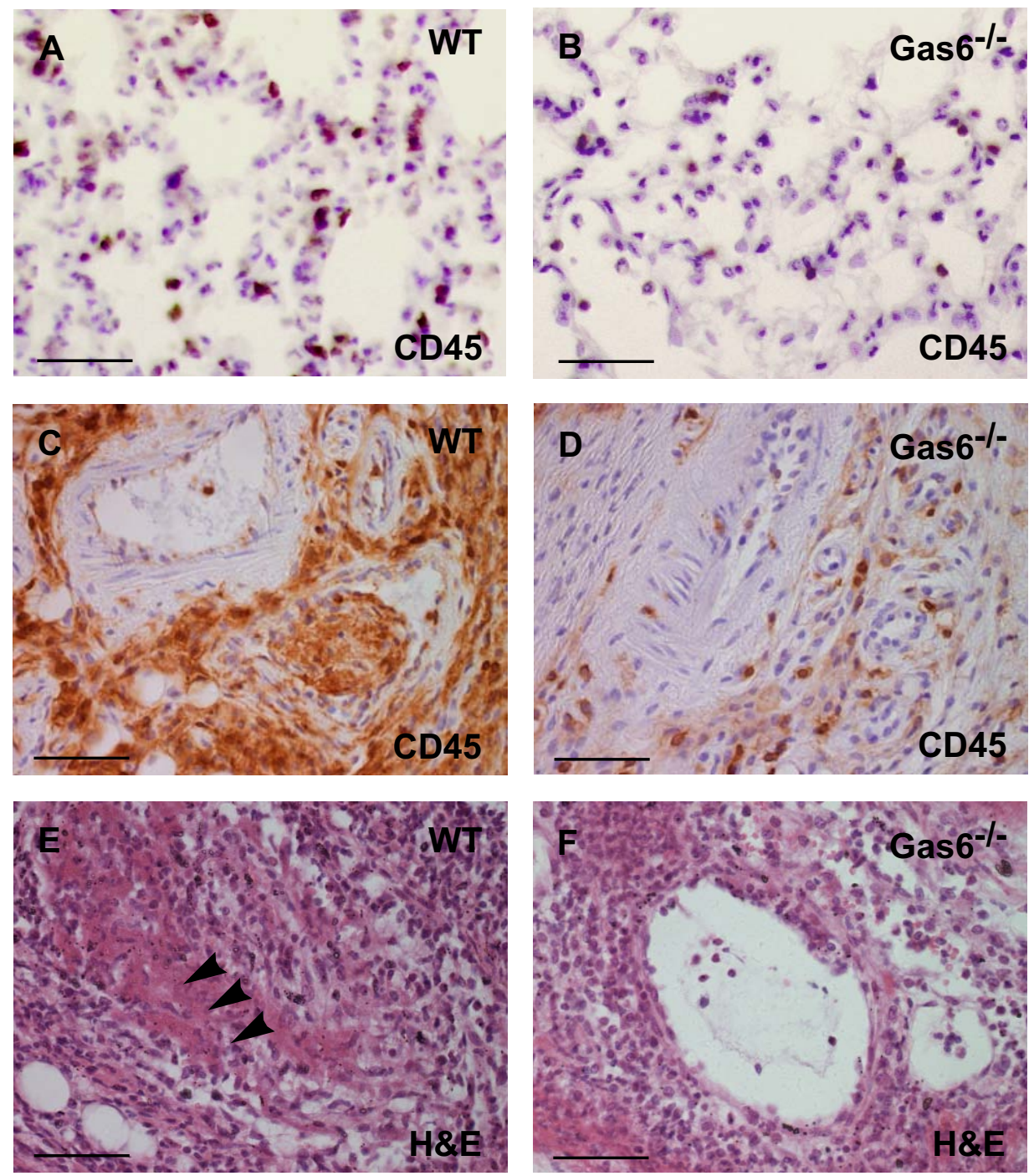

Figure 3 

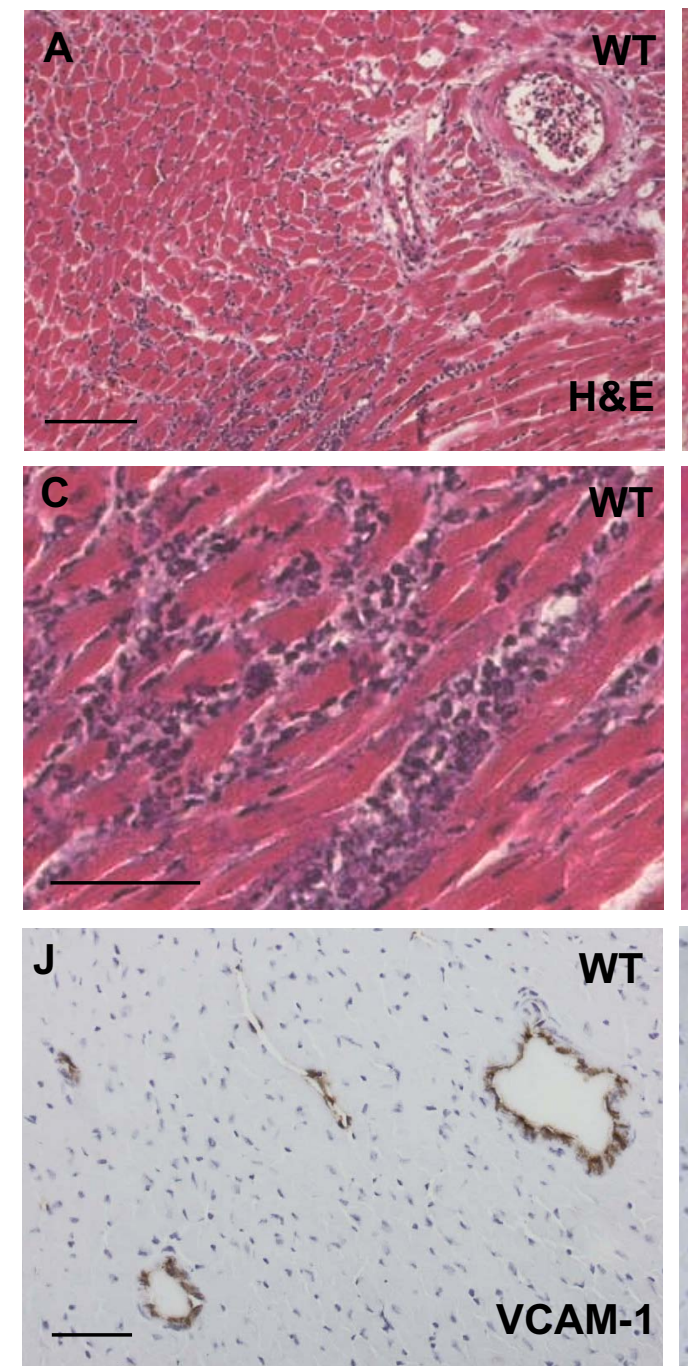

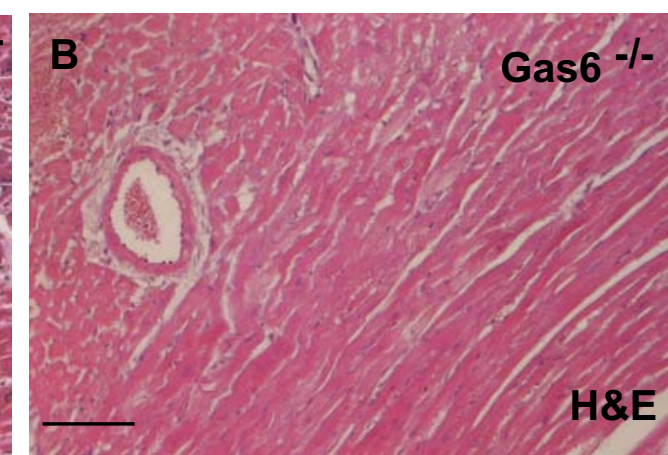

G
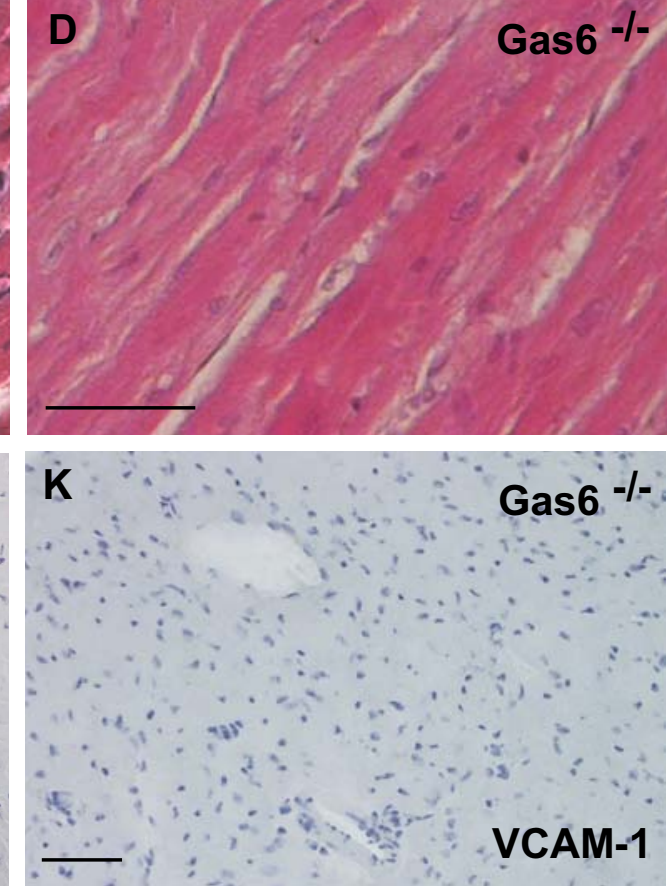
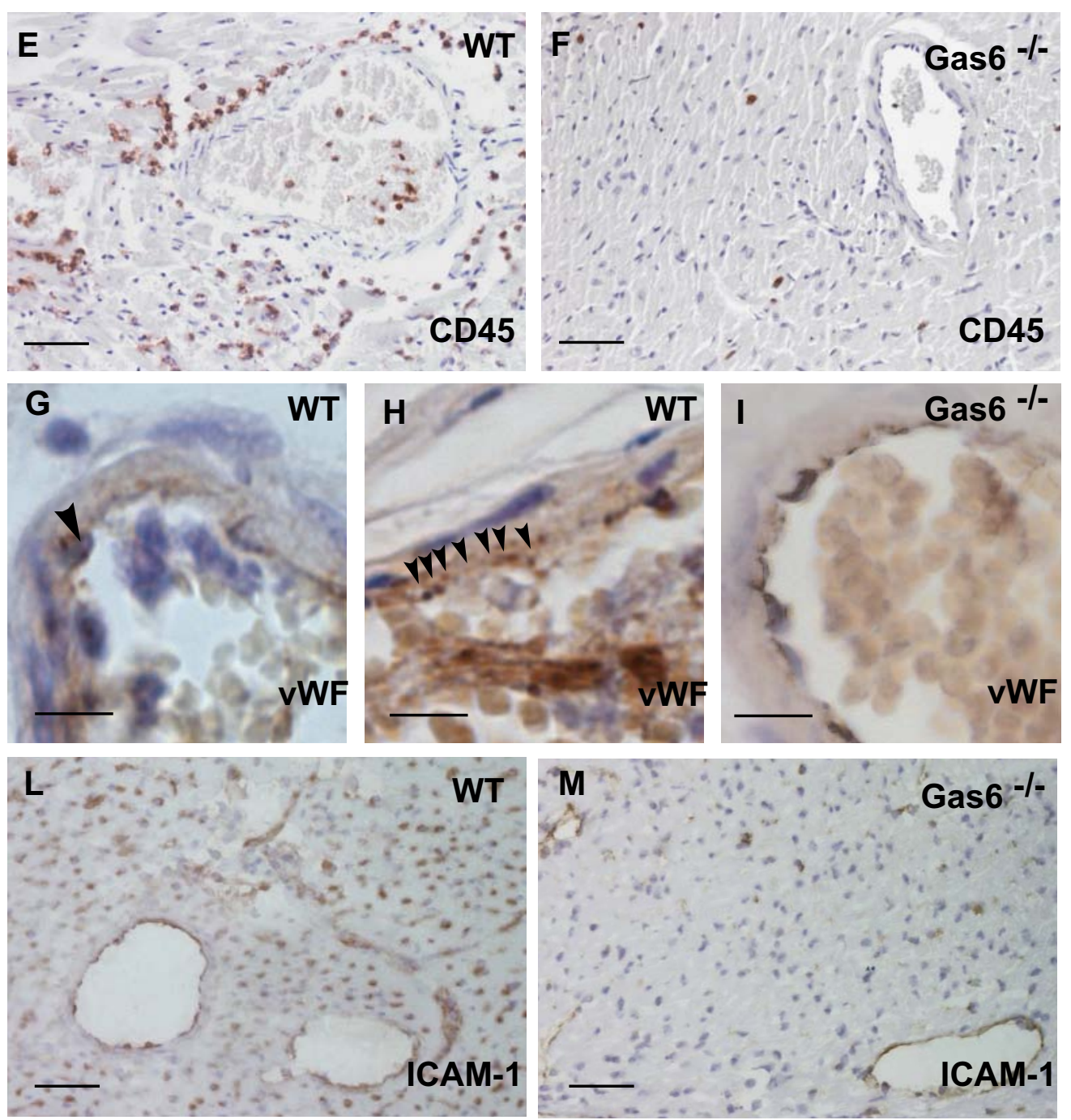

Figure 4 

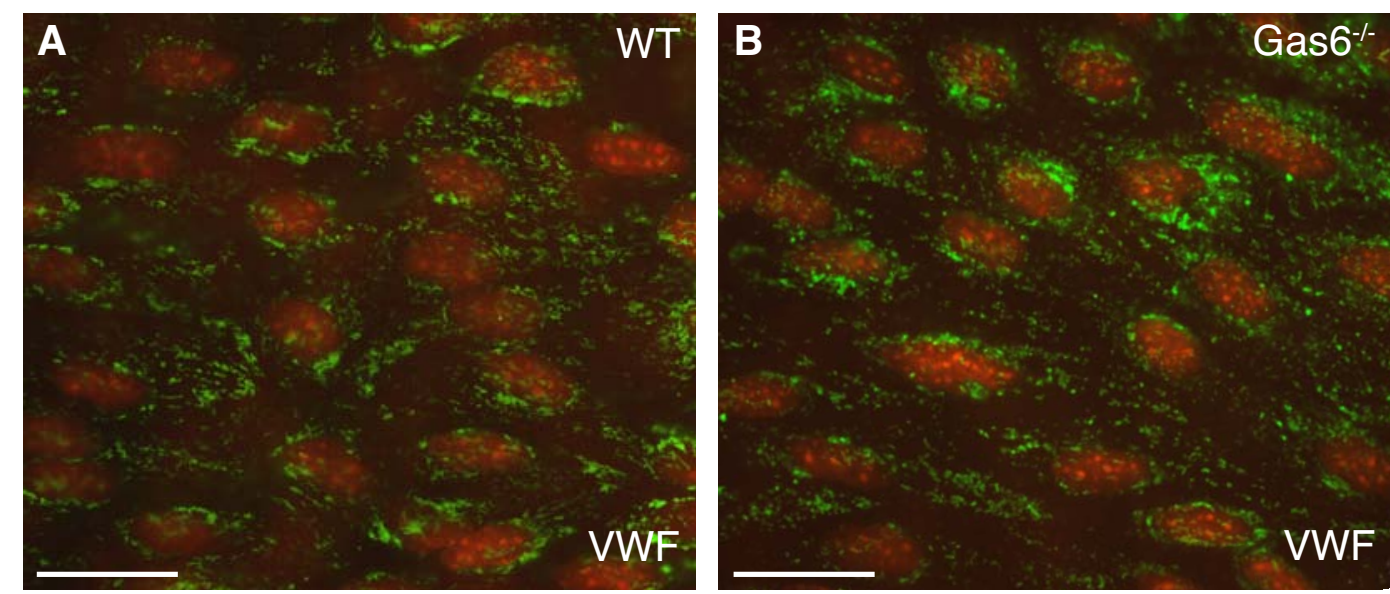

Supplemental Figure 1 


\section{SUPPLEMENTAL INFORMATION}

\section{SUPPLEMENTAL FIGURE LEGENDS}

Supplement Figure $\mathbf{S 1 : A , B}$, Immunolabeling of aortic whole mounts for von Willebrand factor (VWF) revealed an identical labeling of VWF-positive Weibel-Palade bodies in the ECs of WT and Gas6 $^{-/-}$aorta. Scale bar: $20 \mu \mathrm{m}$ in panels A,B.

\section{SUPPLEMENTAL METHODS}

\section{Determination of Weibel-Palade body content}

To determine the amount of Weibel-Palade bodies in WT and Gas6 ${ }^{-/}$ECs, we perfused WT and Gas6 $^{-/-}$mice with $4 \%$ phosphate buffered paraformaldehyde. The aorta was dissected and opened via a longitudinal ventral incision, flat mounted for $1 \mathrm{~h}$ in the same fixative, rinsed and processed as whole mount in an immunofluorescent staining for von Willebrand factor (VWF). Immunostained aorta pieces were analyzed using confocal microscopy. The 3D reconstruction of the confocal image stacks and volume calculation of VWF-stained granules (Weibel-Palade bodies) were accomplished by using IMARIS V.5.5 software (Bitplane). Image stacks of WT and $\mathrm{Gas6}^{-/-}$aortas contained on average a similar number of ECs (data not shown).

\section{FACS analysis}

Flow cytometric analysis of platelet-leukocyte conjugates were performed as described previously ${ }^{1,2}$ In brief, peripheral blood was repetitively sampled via the retro-orbital plexus from LPS-treated mice (20 or $40 \mu \mathrm{g} / \mathrm{g}$ ) and anti-coagulated via $4 \%$ sodium citrate, hirudin $(200 \mu \mathrm{g} / \mathrm{ml})$ and $\mathrm{G} 4120(10 \mu \mathrm{g} / \mathrm{ml})$. After fixation and red blood cell lysis, cells were double-labeled with FITC-labeled anti- $\alpha_{1 \mathrm{lb}} \beta_{3}$ (CD41/61, Emfret) in combination with PElabeled anti-CD45 (BD Biosciences). Because of more reliable gating of granulocytes than of monocytes in murine blood, $\mathrm{CD} 41 / 61^{+} \mathrm{CD} 45^{+}$platelet-granulocyte conjugates were enumerated. 


\section{Animal models}

Administration of endotoxin: For systemic injection, endotoxin (E. coli lipopolysaccharide, serotype 0111:B4 from Sigma) was injected i.p. in 10-12 week old mice (20 $\mu \mathrm{g}$ of LPS per $\mathrm{g}$ of body weight). After $4 \mathrm{~h}$, lungs were dissected, fixed, embedded in paraffin, sectioned and stained with H\&E or immunolabeled with antibodies to CD45 (rat monoclonal, 1:20, BD Biosciences). Myeloperoxidase (MPO) activity was assayed using a modification of a previously described protocol ${ }^{3}$. Briefly, part of the left lung was removed, weighed and homogenized in $1.5 \mathrm{ml}$ of phosphate buffer and centrifuged (20000 x g, $20 \mathrm{~min}$ ). Lung precipitates were resuspended in $0.5 \mathrm{ml}$ of phosphate buffer with $14 \mu \mathrm{M}$ hexadecil trimetil ammonium bromide, sonicated and exposed to 3 freeze-thaw cycles, incubated for 2 hours at $60^{\circ} \mathrm{C}$ and centrifuged $(15000 \times \mathrm{g}, 15 \mathrm{~min})$. Twenty $\mu \mathrm{l}$ of supernatants were incubated for 15 min with substrate buffer (150 $\mu$ of phosphate buffer supplemented with 5 mM EDTA), tetramethyl-benzidine (10 $\mu \mathrm{l}$ of $5 \mathrm{mg} / \mathrm{ml}$ in DMSO) and $\mathrm{H}_{2} \mathrm{O}_{2}(10 \mu \mathrm{l}$ of a $0.5 \%$ solution) and absorbance $(460 \mathrm{~nm})$ was measured. For the local Schwartzman reaction, endotoxin (20 $\mu \mathrm{l}$ of $2.5 \mathrm{mg} / \mathrm{ml}$ ) was injected into the right footpad of both WT and $\mathrm{Gas}^{-/-}$mice as described ${ }^{4}$. Saline was injected into the left footpad as a control. After 5 days, mice were sacrificed and both right and left footpads were excised, fixed in 1\% paraformaldehyde overnight and embedded in paraffin. Seven $\mu$ m sections were stained with H\&E and CD45 (see above). Vessels were scored for the presence of thrombi and the number of CD45 ${ }^{+}$ cells per area was calculated (counted in 20 standard fields at a magnification of 630x).

Heart transplantation model: Mouse hearts (of $100 \%$ C57BL/6 WT or Gas6 ${ }^{-/-}$mice) were heterotopically transplanted as primary vascularized grafts in the neck of syngeneic WT or Gas6 $^{-/-}$recipient mice as previously described ${ }^{5}$. Briefly, hearts were harvested from donors euthanized by $\mathrm{CO}_{2}$ asphyxiation. For induction of warm ischemia injury, donor hearts were left in situ at room temperature for $45 \mathrm{~min}$ before prelevation from the donor animals. Our previous experiments showed that warm ischemia injury caused remarkable pathological injury, but did not interfere with initial graft beating immediately after establishing the blood circulation. Mouse donor hearts were subsequently transplanted 
heterotopically in the cervical region of recipient mice. The recipients were anesthetized by Enflurane (Abbott), supplemented with oxygen through a semiclosed circuit inhalation system. The aorta and pulmonary artery of the donor were anastomosed to the carotid artery and jugular vein of the recipient by microsuture techniques. Spontaneous contractile activity was initiated by reperfusion of the graft. Cardiac grafts were functionally assessed by daily palpation, and graft destruction, as a consequence of an extended warm transplant ischemia time, was diagnosed by cessation of spontaneous contractile activity. Mouse cardiac grafts were removed for histological analysis at 3, 10 or 30 days after transplantation or immediately after cessation of graft beating, cryo-embedded or fixed in $1 \%$ phosphate buffered paraformaldehyde overnight and embedded in paraffin. Seven $\mu \mathrm{m}$ paraffin sections were used for analysis of general heart morphology after H\&E staining or immunostaining for CD45 (see above), or VWF (rabbit polyclonal, 1:500, Dakocytomation). Seven $\mu \mathrm{m}$ cryo-sections were briefly fixed in aceton and immunostained with a biotinylated rat anti-VCAM-1 (1:50, BD Biosciences) and a rat anti-ICAM-1 (CD54, 1:100, Seikagaku) as described above.

\section{References}

1. Appeldoorn CC, Bonnefoy A, Lutters BC, et al. Gallic acid antagonizes P-selectin-mediated platelet-leukocyte interactions: implications for the French paradox. Circulation. 2005;111:106112.

2. Pitchford SC, Momi S, Giannini S, et al. Platelet P-selectin is required for pulmonary eosinophil and lymphocyte recruitment in a murine model of allergic inflammation. Blood. 2005;105:20742081.

3. Bradley PP, Priebat DA, Christensen RD, Rothstein G. Measurement of cutaneous inflammation: estimation of neutrophil content with an enzyme marker. J Invest Dermatol. 1982;78:206-209.

4. Carmeliet P, Schoonjans L, Kieckens L, et al. Physiological consequences of loss of plasminogen activator gene function in mice. Nature. 1994;368:419-424.

5. Lin Y, Goebels J, Xia G, Ji P, Vandeputte M, Waer M. Induction of specific transplantation tolerance across xenogeneic barriers in the T-independent immune compartment. Nat Med. 1998;4:173-180. 